\title{
Consumer Spending and Consumer Confidence in South Africa: Cointegration Analysis
}

\author{
John Khumalo \\ University of South Africa, Pretoria, South Africa \\ khumamj@unisa.ac.za
}

\begin{abstract}
The study uses the time series data covering the period 1980Q1 to 2012Q3 to test the existence of any possible long run relationship between consumer spending and consumer confidence in South Africa. The analysis is done using the Vector Auto-Regressive (VAR) model, with the unit root and the direction of causation also tested before any inference can be concluded on this relationship. The unit root tests using the DF-GLS as well as the Ng-Peron show that consumer spending, consumer confidence and economic growth are integrated of order zero $\sim \mathrm{I}(0)$. Causality results on the other hand reveal that causation runs from consumer confidence to consumer spending and from economic growth to consumer spending in South Africa. The non-existence of unit root compels the establishment of the long-run relationship that leads us to performing VECM to establish short-run and long-run dynamics. Our results indicate that the positive effect of consumer confidence cannot be refuted in South Africa and that it exerts a significant and positive impact on consumer spending, hence aggregate spending.
\end{abstract}

Keywords: Consumer confidence, Consumer spending, Cointegration, VECM, Impulse response function

\section{Introduction}

The South African economy has not yet fully recovered from the recent financial crisis and this has had an impact on consumer spending. It cannot be ignored that confidence plays an important part in determining private consumer spending and such confidence does influence the real economy as a whole. Consumer confidence measures the degree of optimism that consumers feel about the state of the economy and their personal financial situation. Higher confidence leads to higher spending, as such boots economic expansion because consumers tend to make more purchases as opposed to when the confidence is low. Such low confidence will be reflected in more consumers saving more as they perceive some financial distress in the future. Brand (2011) asserts that consumer confidence is one of the indicators that could signal changes in economic activity and could be valuable to forecast and improve consumption based on economy's recent, current and expected conditions. The relationship between consumer confidence and consumer spending cannot be ignored, as some literature conceptualised. Dees \& Brinca (2011) had indicated that confidence has been justified for precautionary savings arguments. It is therefore the contention of this study to establish the relationship between consumer spending and confidence in the case of South Africa.

The second quarter of 2013 was characterised by an increase of the consumer confidence from -7 percent to 1 percent (BER, 2013). The consumer confidence averaged 5 percent from 1993 to 1999. The first quarter of 1993 was seen with a - 9 percent, which fell further in second quarter to - 12 percent, averaging - 2.75 in that year. This shows that consumers were less optimistic in year prior to the 1994 democratic elections about the state of the economy. Consumption on the other hand fell by $0.47 \%$ between the second quarter of 1993 and third quarter $1993^{1}$. Confidence increased further between the years 2000 and 2009 with an average of 5.2075 percent, indicating an increase of about 0.21 percent in those years. The years 2010 to 2013 second quarter showed some degree of confidence amongst the consumers. 2008 experienced a low confidence of about - 3 percent, which might have resulted from the financial crisis and joblessness. The historic trend on consumer spending in South Africa is shown in figure 1 below.

\footnotetext{
${ }^{1}$ Analysis based on figure 1 below
} 
Figure 1: Consumer spending 1993Q1 - 2012Q3 South Africa

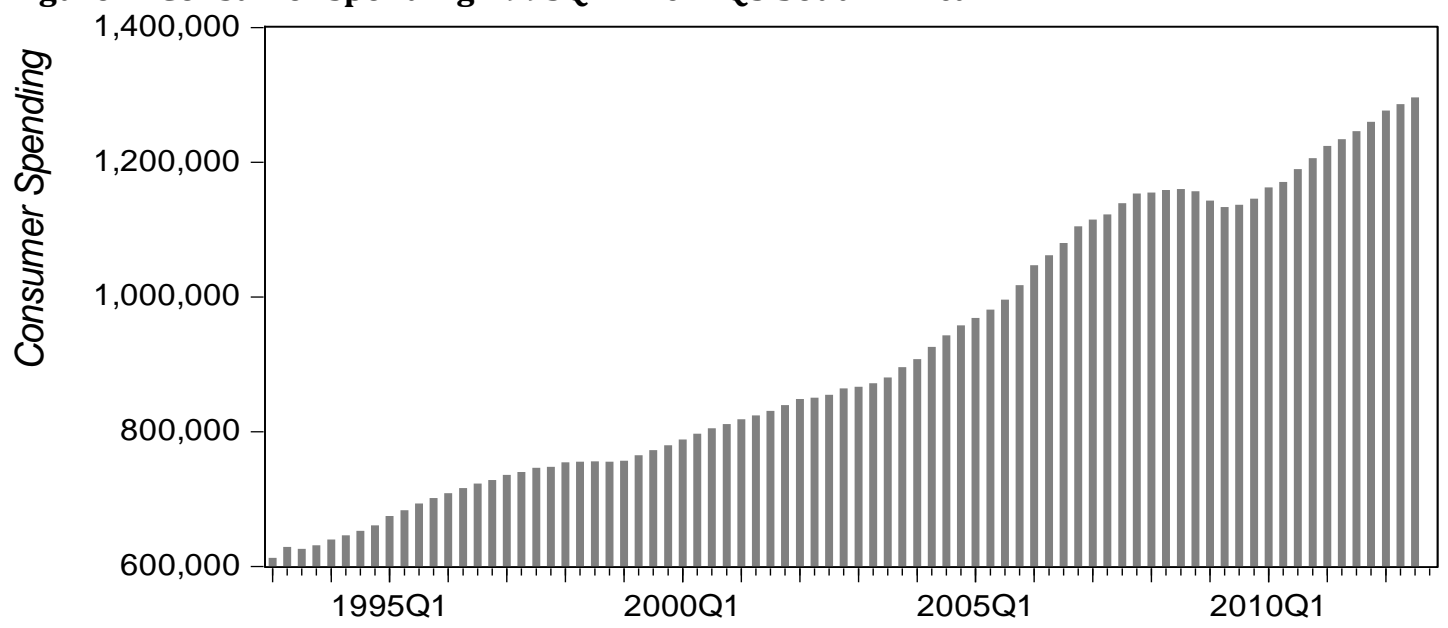

Sample period

The figure below shows the trend of consumer confidence over the years 1993 to 2012. There have been some mixed reactions of the consumers as shown by figure 2 .

Figure 2: Consumer confidence 1993Q1 - 2012Q3 South Africa

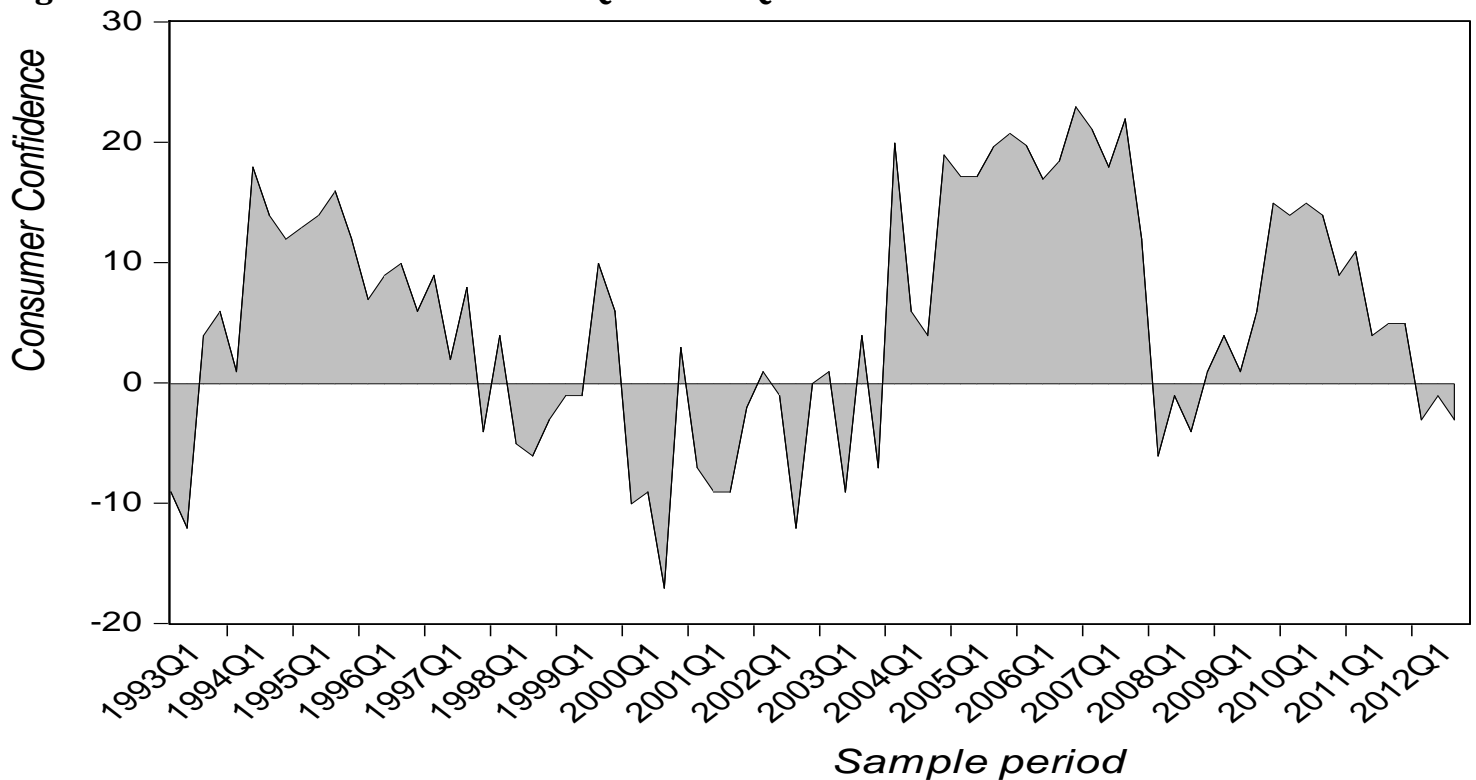

The purpose of this study is to empirically examine the effect (if any) of consumer confidence on consumer spending in South Africa based on the premise of the permanent income hypothesis (PIH) advocated by Friedman (1957 \& 2008).

\section{Literature Review}

This study may not be the first of its nature that tries to find the link between consumer spending and consumer confidence, other studies such as Dees \& Brinca (2011), Lahiri, Monokroussos \& Zhao (2012), Bram \& Ludvigson (1998), Carroll, Fuhrer \& Wilcox (1994), Croushore (2005), Fuhrer (1993), Ludvigson (2004) and Souleles (2004) among other tried to establish the link. Knowing this relationship will provide significant information for policy formulation at both local and national level. Adrangi \& Macri (2010) using cointegration of disaggregated expenditures finds that consumer confidence is regarded as a determining factor for expenditures on consumer durable goods only in the United States of America (USA). Dees \& Brinca (2011) also attempt to establish if consumer confidence can be used as a predictor of consumption spending in the USA and the Euro area. Using the VAR, they find that consumer confidence can in some instances be a reliable predictor of consumer spending in both the USA and the Euro area. 
Golinelli \& Giuseppe (2004) studied the predictive role of consumer confidence indices as a leading and coincident indicator of economic activity in France, Germany, Italy, the UK, the USA, Japan, Canada and Australia using the VAR and found that consumer confidence indices have some predictive ability in forecasting the economic activity under certain assumptions and restrictions. Chua \& Tsiaplias (2009) on the other hand used the Bayesian error correction approach to determine if disaggregation of consumer sentiment data into its sub-components improves the capacity to forecast GDP and consumption in Australia. The results show that disaggregated consumer sentiment data consistently increases the accuracy of GDP and consumption forecasts. Some of the studies (see Fazel, 2005) are of the view that consumer confidence cannot be used as a predictor of aggregate consumption in the USA. Using a multivariate single equation, Fazel (2005) finds no relationship between consumer confidence and consumption expenditure. In view of these studies, mostly U.S.A. based, this study intends find establish the long run relationship using the VAR modelling technique.

\section{Econometric Specification of the model:}

The variables chosen in this study are based on the economic theory and their expected contribution to the model itself. Romer (2009) indicated that consumer spending depends on several things, including but not limited to income, taxes, confidence as well as wealth. The model specification is assumed to be a VAR system though the variables under consideration are consumption expenditure and consumer confidence. Other explanatory variables ${ }^{2}$ that enter the model are believed to have an impact on consumption. The general dynamic form of the econometric model used in this study is:

$$
\operatorname{COSP} P_{t}=\beta_{0}+\sum_{\mathbf{i}=\mathbf{1}}^{\mathbf{k}} \beta_{1 i} \operatorname{COSP} P_{t-i}+\sum_{\mathbf{i}=\mathbf{0}}^{\mathbf{k}} \beta_{t i} Y_{t-i}+\delta_{0} D_{\mathbf{t}}+v_{t}
$$

Where, $\operatorname{COSP}_{\mathrm{t}}=$ consumer spending, $\mathrm{Y}_{\mathrm{t}-\mathrm{i}}=$ represents the set of all explanatory variables to be included in the model and their lags (thus, $\mathrm{CCONF}_{t}=$ consumer confidence $\mathrm{UN}_{t}=$ unemployment, $\mathrm{PTax}_{t}=$ personal income tax (PAYE), $D_{t}=$ represents a set of deterministic terms (dummies, trends and others). $\mathrm{V}_{\mathrm{t}}=$ well behaved error term. Therefore, specifying equation (1) as a VAR system of equations gives equation (2), which is compactly written as equation (3):

$$
\begin{aligned}
& Y_{\mathrm{t}}=\delta_{0} D_{\mathrm{t}}+\delta_{1} Y_{\mathrm{t}-\mathbf{1}}+\delta_{\mathbf{2}} Y_{\mathrm{t}-2}+\ldots \ldots \ldots \ldots \ldots \ldots+\delta_{\mathrm{k}} Y_{\mathrm{t}-\mathrm{k}}+\pi_{\mathrm{t}} \\
& Y_{\mathrm{t}}=\delta_{\mathbf{0}} D_{\mathrm{t}}+\sum_{\mathrm{i}=\mathbf{1}}^{\mathrm{k}} \delta_{\mathrm{i}} Y_{\mathrm{t}-\mathbf{i}}+\pi_{\mathrm{t}}
\end{aligned}
$$

Where $\sum_{\mathbf{i}=\mathbf{1}}^{\mathbf{k}} \delta_{\mathbf{i}} Y_{\mathbf{t}-\mathbf{i}}=$ summation of vector of lagged endogenous variables in the system. $Y_{t}$ is a nx1 column vector of all variables that enter system ${ }^{3}, D_{t}=$ Vector holding deterministic terms (intercepts, trends, dummies, and so forth), $\pi_{t}=\mathrm{nx} 1$ dimensional vector of multivariate random errors with mean zero and covariance matrix $\Omega$, thus error terms are assumed contemporaneously correlated but not auto correlated, $\delta_{i}=$ matrices of coefficients to estimated.

Formally stated, the assumptions of the model are:

$$
\begin{aligned}
& \boldsymbol{\varepsilon}_{\mathbf{i t}} \sim \mathbf{N}\left(\mathbf{0}, \mathbf{w}_{\mathrm{ii}}\right), \forall \text { all t, and i }=1,2 \ldots \mathrm{n}, \text { where } \boldsymbol{w}_{\text {ii }}=\operatorname{var}\left(\varepsilon_{i t}\right) \\
& \quad \mathbf{E}\left(\boldsymbol{\varepsilon}_{\mathrm{it}} \boldsymbol{\varepsilon}_{\mathrm{is}}\right)=\mathbf{0}, \forall \mathrm{t} \neq \mathrm{s}, \mathrm{i}=1,2 \ldots \ldots 6 \\
& \mathbf{E}\left(\boldsymbol{\varepsilon}_{\mathrm{it}} \boldsymbol{\varepsilon}_{\mathrm{jt}}\right)=\mathbf{w}_{\mathrm{ij}}, \forall \text { all t, and i,j }=1,2 \ldots \mathrm{n} \text {, where } \boldsymbol{w}_{i j}=\operatorname{cov}\left(\varepsilon_{i t} \varepsilon_{j t}\right) \\
& \text { Or in matrix form }
\end{aligned}
$$

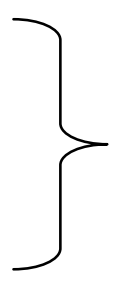

\footnotetext{
2 Tax, Inflation, unemployment

${ }^{3}$ Note that the variables that enter the VAR system are not determined apriori, rather depend on results from stationarity test.
} 


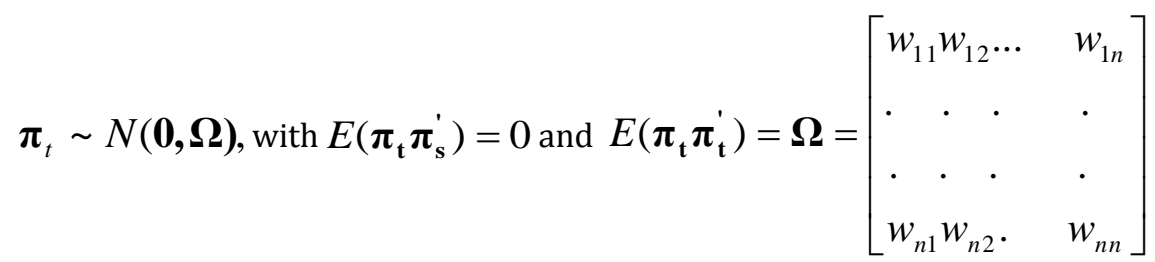

Therefore, in order to capture the short-run dynamics of variables in the system, equation (2) is parameterized to give the VECM specification, given in equation (6) below, which is trimly expressed as equation (7):

$$
\begin{aligned}
& \Delta Y_{\mathrm{t}}=\psi D_{\mathrm{t}}+\prod Y_{\mathrm{t}-1}+\Gamma_{1} \Delta Y_{\mathrm{t}-1}+\Gamma_{2} \Delta Y_{\mathrm{t}-2}+\ldots \ldots \ldots \ldots \ldots \ldots \ldots+\Gamma_{\mathrm{k}-1} Y_{\mathrm{t}-\mathrm{k}+1}+\pi_{\mathrm{t}} \\
& \Delta Y_{\mathbf{t}}=\psi D_{\mathbf{t}}+\sum_{\mathbf{i}=\mathbf{1}}^{\mathbf{k}-1} \Gamma_{\mathbf{i}} \Delta Y_{\mathbf{t}-\mathbf{i}}+\prod Y_{\mathbf{t}-\mathbf{1}}+\Gamma_{\mathbf{k}-1} Y_{\mathbf{t}-\mathbf{k}+\mathbf{1}}+\pi_{\mathbf{t}}
\end{aligned}
$$

where matrix $\boldsymbol{\Pi}=\boldsymbol{\alpha} \cdot \boldsymbol{\beta}^{\prime}$ (thus $\boldsymbol{\Pi}$ is decomposed into two matrices of dimensions [n $\mathrm{nr}$ ], and $\mathrm{r}$ is the number of cointegrating vectors), $\alpha$ is a matrix of adjustment coefficients or the loading matrix and contains the short run dynamics while $\beta$ is the matrix containing the long run equilibrium relationships or long run coefficients or elasticities. The VAR analysis employs the Johansen cointegration test advocated by Johansen (1988) and Johansen \& Joselius (1990).

Data types and source: The model estimated in this study utilized quarterly time series data covering the period 1993Q1 to 2012Q3. The data was sourced from www.tradingeconomics.com while data on consumer confidence was sourced from Bureau of Economic Research South Africa (BER ${ }^{4}$ ). GDP was used as a proxy for economic growth and calculated as: $\mathrm{GDPG}_{\mathrm{t}}=\left[\left(\mathrm{GDP}_{\mathrm{t}}-\mathrm{GDP}_{\mathrm{t}-1}\right) / \mathrm{GDP}_{\mathrm{t}-1}\right]^{*} 100$.

\section{Findings}

Granger Causality Analysis: The results of causality test are reported in table 2 below. We conclude that there is unidirectional causality with causality running from consumer confidence to consumer spending. The study excluded other explanatory variables such as personal tax, inflation and unemployment after the preliminary tests showed that these variables were not statistically significant in explaining consumer spending. As much as other studies could come to a different conclusion about the dropping of these

\begin{tabular}{|c|c|c|c|}
\hline Dependent: COSP & Chi-sq & df & Prob. \\
\hline CCONF & 1.881426 & 2 & 0.3903 \\
\hline GDPG & 12.97816 & 2 & $0.0015^{*}$ \\
\hline All & 16.10672 & 4 & $0.0029 *$ \\
\hline \multicolumn{4}{|c|}{ Dependent variable: CCONF } \\
\hline COSP & 0.928008 & 2 & 0.6288 \\
\hline GDPG & 2.453339 & 2 & 0.2933 \\
\hline All & 3.751444 & 4 & 0.4407 \\
\hline \multicolumn{4}{|c|}{ Dependent variable: GDPG } \\
\hline COSP & 2.245795 & 2 & 0.3253 \\
\hline CCONF & 4.688602 & 2 & $0.0959^{* * *}$ \\
\hline All & 8.592019 & 4 & $0.0721^{* * *}$ \\
\hline
\end{tabular}
variables, they are found to be insignificant for South Africa.

Table 2: VAR Granger Causality/Block Exogeneity Test results

${ }^{*}, * *,{ }^{* * *}$ represent $1 \%, 5 \%$ and $10 \%$ respectively

\footnotetext{
${ }^{4}$ http://www.ber.ac.za
} 
The results of exogeneity test indicate that not all variables can be treated as endogenous. The variables can be treated as endogenous jointly but not always individual. The pair wise Granger causality shows that there is unidirectional causation from economic growth and consumer confidence to consumer spending in South Africa.

Unit Root and Stationarity Analysis: In empirical research, regressing of one non-stationary series on the other may lead to spurious regression, which adversely affects the validity of the standard statistical tests ( $\mathrm{t}$ and F-tests). Various solutions are proposed to deal with non-stationary time series; these include differencing of the series to reach stationarity. The most notable tests include the ADF proposed by Dickey \& Fuller (1979) as well as the PP by Phillips \& Perron (1988), which were found to lack power and hence a development of other tests.

The DF-Generalized Least Squares (DF-GLS) test: This detrending test was suggested by Elliott, Rothenberg \& Stock in $1996^{5}$. These Authors optimized the power of the ADF test by detrending. The test is based on testing the null hypothesis that $\phi_{0}=0$ given the following regression:

$$
\Delta Z_{t}^{\mathrm{d}}=\varphi_{0} Z_{t}^{\mathrm{d}}+\varphi_{1} \Delta Z_{\mathrm{t}-1}^{\mathrm{d}}+\ldots \ldots \ldots \ldots \ldots+\varphi_{\mathrm{p}} \mathbf{Z}_{\mathrm{t}-\mathrm{p}}^{\mathrm{d}}+\varepsilon
$$

where $Z_{t}^{d}$ is the de-trended series $Z_{\mathrm{t}}$. The null hypothesis of the test is that $Z_{t}^{d}$ has a random walk trend, possibly with a drift as follows:

$$
\mathbf{Z}_{\mathbf{t}}^{\mathbf{d}}=\mathbf{Z}_{\mathbf{t}}-\hat{\boldsymbol{\delta}}_{\mathbf{0}}-\hat{\boldsymbol{\delta}}_{\mathbf{1}} \mathbf{t}
$$

Two possible alternative hypotheses accrue to this test:

(a) $Z_{t}$ is stationary about a linear trend

(b) $Z_{t}$ is stationary with a (possibly) non-zero mean, but with no linear time trend.

Under the first alternative hypothesis, the DFGLS test is performed by first estimating the intercept and the trend using the generalized least squares technique. This estimation is performed by generating the following variables:

$$
\begin{aligned}
& \overline{\mathbf{Z}}=\left[\mathbf{Z}_{1},(\mathbf{1}-\overline{\boldsymbol{\alpha}} \mathbf{L}) \mathbf{Z}_{2} \ldots \ldots \ldots \ldots \ldots \ldots \ldots \ldots \ldots,(1-\overline{\boldsymbol{\alpha}} \mathbf{L}) \mathbf{Z}_{\mathrm{T}}\right] \\
& \left.\bar{W}=\left[Z_{1},(1-\bar{\alpha} \mathbf{L}) W_{2} \ldots \ldots \ldots \ldots \ldots \ldots \ldots \ldots,(1-\bar{\alpha} \mathbf{L}) W_{T}\right]\right\} \\
& \text { and } \mathrm{W}_{\mathrm{t}}=(1, \mathrm{t}) \quad \bar{\alpha}=1+\frac{\bar{C}}{T}
\end{aligned}
$$

where T represents the number of observations for $\mathrm{Z}_{\mathrm{t}}$ and $\bar{C}$ is fixed at $-13.7^{\mathrm{a}}$. Then an OLS regression is performed on the following equation:

$$
\mathbf{Z}=\boldsymbol{\delta}_{0} \mathbf{W}+\overline{\boldsymbol{\delta}}_{\mathbf{1}} \mathbf{W}_{\mathbf{t}}+\boldsymbol{\varepsilon}_{\mathrm{t}}
$$

and the OLS estimators $\hat{\delta}_{0}$ and $\hat{\delta}_{1}$ are then used to remove the trend from $\mathbf{Z}_{\mathrm{t}}$ above. Finally, the ADF is performed on the transformed variable by fitting the OLS regression given by equation (13) below:

$$
\Delta Z_{t}^{d}=\varphi_{0}+\rho Z_{t-1}^{d}+\sum_{j=1}^{k} \beta_{j} \Delta Z_{t-j}^{d}+\mu_{t}
$$

From equation (9), the null hypothesis that $\rho=0$ is tested using the tabulated critical values provided by Elliot et al. (1996). Under the second alternative hypothesis, the DFGLS test is implemented as before but this time $\bar{C}$ is fixed at -7 in the equation of $\bar{\alpha}$, above. Then $\mathbf{Z}_{\mathbf{t}}^{\mathbf{d}}=\mathbf{Z}_{\mathbf{t}}-\hat{\boldsymbol{\delta}}_{\mathbf{0}}$ is computed and the ADF is

${ }^{5}$ See details of the test in G. Elliott, T.J.Rothenberg, and J.H.Stock, "Efficient Tests for an Autoregressive Unit Root," Econometrica, Vol.64, 1996,pp813-836. 
fitted on the newly transformed variable and the null hypothesis of $\rho=0$ is evaluated using the tabulated critical values. The results pertaining to the most parameterized model are presented in Table 3 . The results indicate that consumer spending (COSPR), consumer confidence (CCONF) as well as economic growth (GDPG) are all stationary at level form. This also suggests that there could be a possibility of the existence of cointegration among these variables.

Ng-Perron unit root test: While the power gains of the DFGLS test are impressive, the simulations by $\mathrm{Ng}$ and Perron (2001) show that the tests exhibit strong size distortions. Ng \& Perron (2001) propose a test for unit root that has good size and power properties. They construct four M-test statistics that are based upon the

$$
\text { GLS }
$$
de-trended data:

$$
M Z_{\alpha}^{G L S}, M S B^{G L S}, M Z_{t}^{G L S}=M Z_{\alpha}^{G L S} \times M S B^{G L S} \text {, and } M P_{T}^{G L S} \text { ) }
$$

These tests have similar size and power properties and simulations show that they perform better than the DFGLS test (Ng and Perron, 2001). Ng and Perron also address the problem of sensitivity of unit root testing to the choice of lag length. They propose the new information criteria, the Modified Information Criteria (MIC). The distinction between the standard information criteria such as the Akaike and the Schwartz Bayesian is that the former takes into account the fact that the bias in the sum of the autoregressive coefficients is highly dependent on the number of lags.

\begin{tabular}{|c|c|c|c|c|c|c|}
\hline Name & $D F-G L S$ & $M Z_{\alpha}^{G L S}$ & $M Z_{t}^{G L S}$ & $M S B^{G L S}$ & $M P_{T}^{G L S}$ & Inference \\
\hline COSPR & $-2.4657^{*}$ & $-10.5872^{* *}$ & $-2.2490^{* *}$ & $0.2124^{*}$ & $2.5185^{*}$ & $\mathrm{I}(0)$ \\
\hline CCONF & $-1.8705^{* *}$ & $-6.2863^{* * *}$ & $-1.7728^{* * *}$ & $0.2820^{* *}$ & $3.8974^{* *}$ & $\mathrm{I}(0)$ \\
\hline GDPG & $-4.4987^{*}$ & $-25.7433^{*}$ & $-3.5835^{*}$ & 0.1392 & 0.9654 & $\mathrm{I}(0)$ \\
\hline
\end{tabular}

Table 3: Unit Root Test Results

***,*** represent level of rejection at $1 \%, 5 \%$ and $10 \%$ respectively

Results from an application of Ng-Perron test show that the unit root hypothesis is rejected at 5 percent level of significance. This is grounded on the fact that the $M Z_{\alpha}^{G L S}$ and $M Z_{t}{ }^{G L S}$ statistics are smaller than the Ng-Perron critical values at 5 percent level of significance, thereby indicating the rejection of the null hypothesis of unit root among these variables. The computed $M S B{ }^{G L S}$ and $M_{T}{ }_{T}^{G L S}$ statistics also appear smaller than Ng-Perron critical values for these statistics at 5 percent level of significance, thereby indicating the rejection of the null hypothesis of unit root at 5 percent level of significance. Therefore, NgPerron test also confirms that variables are $\mathrm{I}(0)$.The stationarity results could be affected by any structural breaks within the sample period under consideration and to ascertain any existence of such breaks, the study used adopted the Bai - Perron test ${ }^{6}$. The results are reported in appendix D, the results indicate that there were no structural breaks detected within the sample period.

Cointegration Analysis: The trace test rejects null hypothesis of zero cointegrating vector at 5 percent level of significance and accepts that of at least one cointegrating vector at 5 percent level of significance. Therefore, the computed trace statistics that are greater than the critical trace values at 5 percent level of significance explain the rejection of the null hypothesis of either zero or one cointegrating vectors. However, in an attempt to pin down the exact number of cointegrating vectors, the maximum eigenvalue test was conducted and the results indicate that there is at most one cointegrating equation. The results of the maximum eigenvalue test reject the hypothesis of zero cointegrating vector at 1 percent level of significance and pins down to one cointegrating vector. See table 4 below on summary of cointegration analysis covering all assumptions.

\footnotetext{
${ }^{6}$ See Bai and Perron (1998 \& 2003a)
} 
Table 4: Cointegration analysis summary

\begin{tabular}{llllll}
\hline Data Trend: & None & None & Linear & Linear & Quadratic \\
\hline Test Type & No Intercept & Intercept & Intercept & Intercept & Intercept \\
& No Trend & No Trend & No Trend & Trend & Trend \\
Trace & 1 & 1 & 1 & 1 & 1 \\
Max-Eig & 1 & 1 & 1 & 1 & 1 \\
\hline
\end{tabular}

*Critical values based on MacKinnon-Haug-Michelis (1999)

The normalised cointegrating equation is given as: $C O S P R-0.0073 C C O N F-0.3213 G D P G=0$ ,which shows that there is a positive relationship between consumer spending and consumer confidence.

Vector Error Correction Model (VECM): The existence of long run relationship between the variables included in the model prompt us to perform the error correction modelling in the VAR and the results are presented below.

Table 5: The VECM Results

\begin{tabular}{llll}
\hline Error Correc. & $\Delta($ COSPR $)$ & $\Delta($ CCONF $)$ & $\Delta($ GDPG $)$ \\
\hline CointEq1 & -0.3826 & 0.2816 & 2.0677 \\
& {$[0.1415)$} & $(2.0476)$ & $(0.5640)$ \\
& {$[-0.97]$} & {$[-2.82]$} & {$[-2.87]$} \\
\hline
\end{tabular}

Note: Numbers in parenthesis (0 are the standard deviations and those in brackets [] are the $t$-values

The VECM results reveal that about 38 percent of the disequilibrium is corrected each quarter by changes in consumer spending in South Africa. This is justified by the coefficient -0.3826 . The error correction suggests the validity of the equilibrium relationship, indicating the existence of market forces that operate to restore long - run equilibrium after a short - run. The variables; economic growth and consumer confidence produced positive coefficients as expected.

Impulse responses functions: The results of the VAR are presented in appendix B below in the form of the impulse response functions. The dashed lines in each graph show the $95 \%$ confidence bands. The impulse response functions are plotted over a 10 - year horizon. It is expected that during the fiscal shock, consumer spending would increase while savings would fall. The increase in consumer spending is shown by solid line increasing in period one up to period four. After the fourth period, consumer spending becomes steady again, though it eventually falls in period five through period ten. The graph that shows response of COSPR to CCONF suggests that the unexpected increase in consumer confidence tends to provide a positive jolt to consumer spending about three years later. COSPR reacts positively to a shock in economic growth (GDPG) rate, meaning that when the economic growth increases, more job opportunities are created and consumer become confidence in spending with the view that the future holds positive results for them.

\section{Conclusion}

The main objective of this study was to establish the impact of consumer confidence on consumer spending in South Africa with the view that higher confidence exerts positively on consumer spending, which then increases aggregate spending. The variables included in the study are consumer spending, consumer confidence and growth of gdp (proxy for economic growth), while the other variables like, personal tax, inflation, unemployment and the rate of interest were dropped due to their insignificance in the model. In order to achieve the study objectives, the study employed a quarterly data covering the period 1993Q1 to 2012Q3. The properties of data revealed that all the variables were stationary as shown by the generalised least squares (DF-GLS) as well as the Ng-Perron tests. The presence of stationarity implies that there exists a long run relationship between the variables included. The regression results show that consumer confidence and economic growth affect consumer spending positively and as a result, increases in aggregate expenditure will be experienced when consumers are highly confident 
about the state of the economy. The cointegration test revealed that there is at most one cointegration vector while the short-run dynamics test (VECM) showed that consumer spending adjusts by about 38 percent each quarter. This was evident from the VECM results presented in table 5 of this study. The VAR impulse response functions also supported the premise of the positive relation between consumer spending and consumer confidence. The overall results of the study indicate that both the private sector and public sector play an important part in influencing spending. This shows that policy makers should take into consideration the welfare effect of consumer confidence and that policy makers can in future use consumer confidence to forecast or predict personal consumption.

\section{References}

Adrangi, B. \& Macri, J. (2011).Consumer confidence and aggregate consumption expenditures in the United States. Review of Economics and Finance, 1, 1- 29.

Bai, J. \& Perron, P. (1998). Estimating and testing linear models with multiple structural changes. Econometrica, 66, 47-78.

Bai, J. \& Perron, P. (2003a). Computation and analysis of multiple structural change models. Journal of Applied Econometrics, 18, 1-22.

Bureau of Economics Research (BER) of South Africa. (2013). Website www.ber.ac.za

Brand, T. H. (2011). On the performance of consumer confidence measurement. OECD/European Commission workshop on International Development in Business and Consumer Tendency Surveys. Available at http://www.oecd.org/std/leading-indicators/49026134.pdf

Bram, J. \& Ludvigson, S. (1998). Does Consumer Confidence Forecast Household Expenditure? A sentiment index horse race. Federal Reserve Bank of New York.

Carroll, C. D., Fuhrer, J. C. \& Wilcox, D. W. (1994). Does Consumer Sentiment Forecast Household Spending? If So, Why? The American Economic Review, 84(5), 1397-1408.

Chua, L. C. \& Tsiaplias, S. (2009). Can Consumer Sentiment and its Components Forecast Australian GDP and Consumption? Journal of Forecasting, 28, 698-711.

Croushore, D. (2005), Do Consumer Confidence Indexes Help Forecast Consumer Spending in Real Time? North American Journal of Economics and Finance, 16, 435-450.

Dees, S. \& Brinca, P. S. (2011). Consumer Confidence as a Predictor of Consumption Spending: Evidence for the United States and the Euro Area. ECB Working Paper No. 1349.Accessed 1 August 2013. Available at http://ssrn.com/abstract $=1852208$.

Dickey, D. \& Fuller, W. (1979).Distribution of estimators for Autoregressive Time Series and Units Roots. Journal of American Statistical Association, 74(366), 427-431.

Elliott, G., Rothenberg, T. J. \& Stock, J. H. (1996). Efficient Tests for an Autoregressive Unit Root. Econometrica, 64, 813 - 836.

Fazel, K. (2005).Consumer's expectations and consumption expenditure. Journal for economic educators, $5(2), 1-5$.

Friedman, M. (1957).Theory of consumption function. Princeton, Princeton University Press.

Friedman, M. (2008).Theory of consumption function. Princeton, Princeton University Press.

Fuhrer, J. C. (1993). What Role Does Consumer Sentiment Play in the U.S. Macro economy? New England Economic Review, 1, 32-44.

Golinelli, R. \& Parigi, G. (2004). Consumer Sentiment and Economic Activity: A Cross Country Comparison. Journal of Business Cycle Measurement and Analysis, 1, 147 - 170.

Johansen, S. (1988).Statistical Analysis of Cointegration Vectors. Journal of Economic Dynamics and Control, 12, 231-54.

Johansen, S. \& Juselius, K. (1990).Maximum Likelihood Estimation and Inference on Cointegration with Application to the Demand for Money. Oxford Bulletin of Economics and Statistics, 52, 169 - 210.

Lahiri, K., Monokroussos, G. \& Zhao, Y. (2012). Forecasting consumption in real time: The role of consumer confidence in surveys, Available at: www.albany.edu/economics/research/workingp/2012/lmz-consent.pdf.

Ludvigson, S. C. (2004). Consumer Confidence and Consumer Spending. Journal of Economic Perspectives, $18(2), 29-50$.

Phillips, P. C. \& Perron, P. (1988).Testing for Unit Roots in Time Series Regression. Biometrika, 75, 335 346.

Ng, S. \& Perron, P. (2001). Lag Length Selection and the Construction of Unit Root Tests with Good Size and Power. Econometrica, 69, 1519 - 1554. 
Romer, C. (2009). The Economic Crisis: Causes, Policies, and Outlook. Testimony before the Joint Economic Committee of Congress, April 30, 2009.

Souleles, N. S. (2003). Expectations, Heterogeneous Forecast Errors, and Consumption: Micro Evidence from the Michigan Consumer Sentiment Surveys. Journal of Money, Credit, and Banking, 36(1), 39-72.

\section{Appendices}

Appendix A: graphical presentation and Residuals COSPR

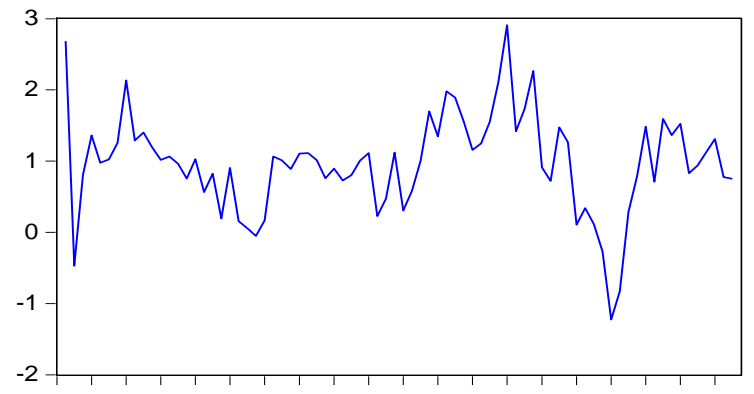

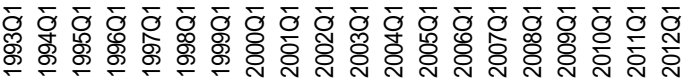
CCONF

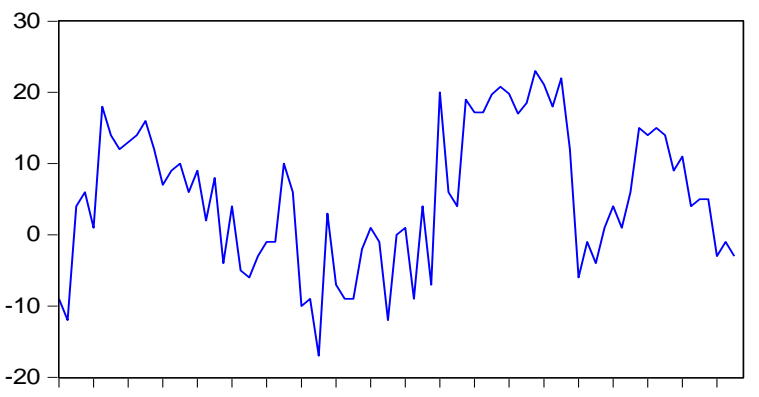

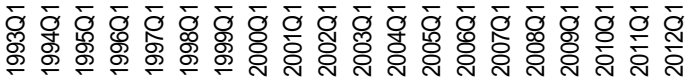
GDPG

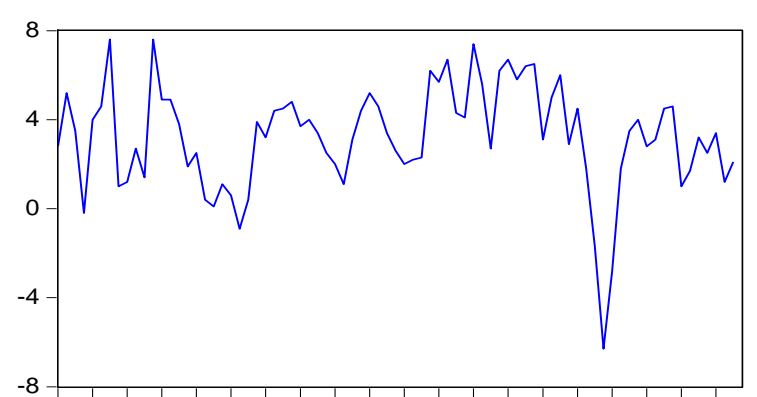

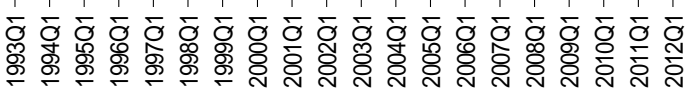

COSPR Residuals

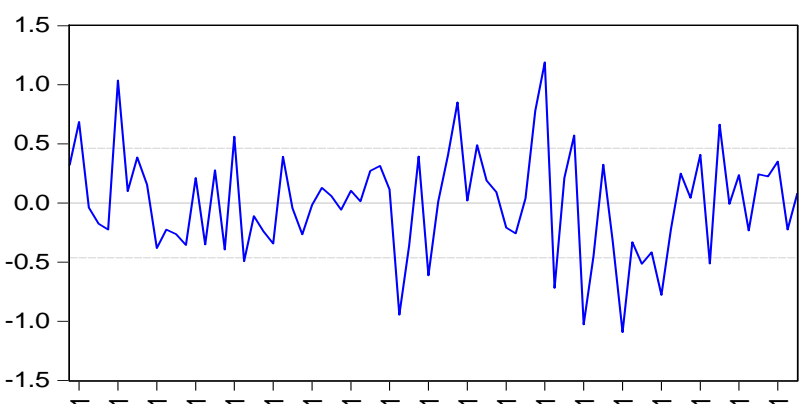

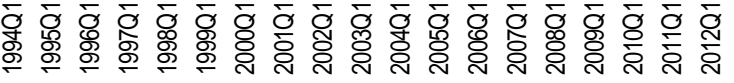
CCONF Residuals
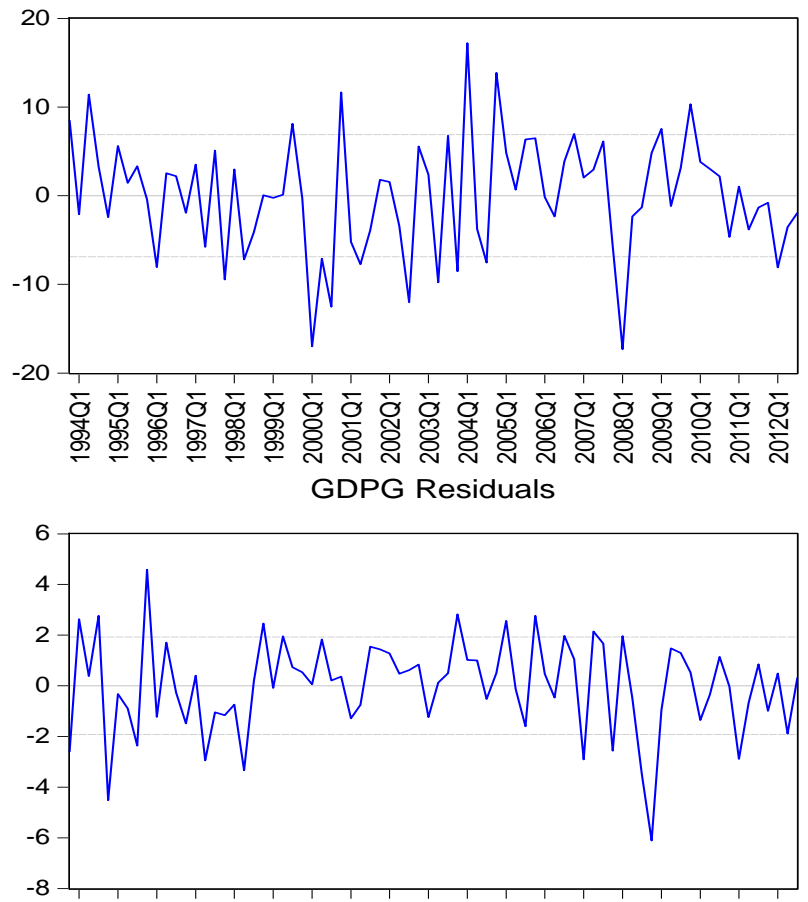

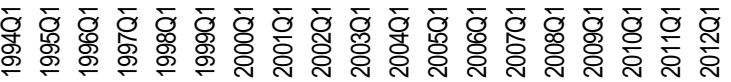


Appendix B: Impulse response functions

Response to Cholesky One S.D. Innovations \pm 2 S.E.

Response of COSPR to COSPR

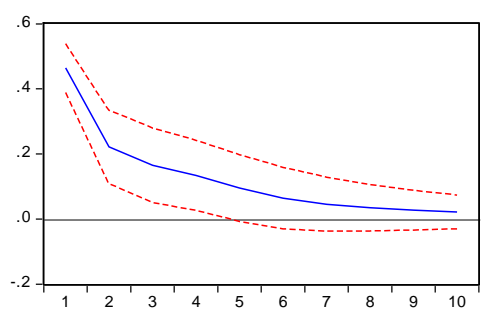

Response of CCONF to COSPR

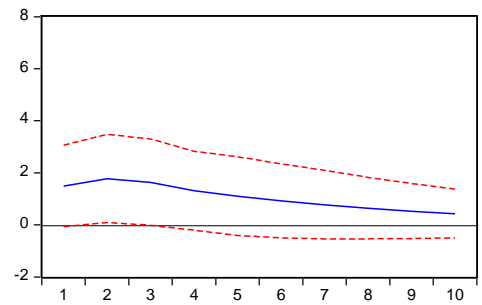

Response of GDPG to COSPR

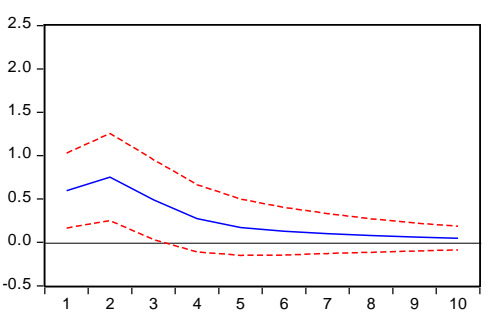

Response of COSPR to CCONF

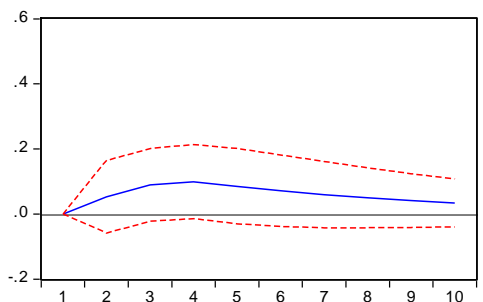

Response of CCONF to CCONF

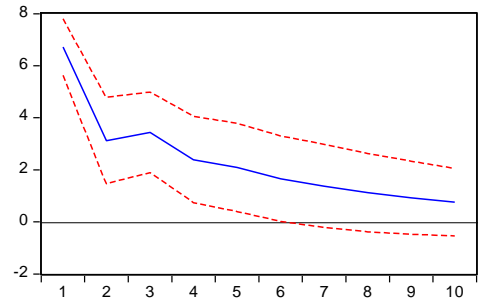

Response of GDPG to CCONF

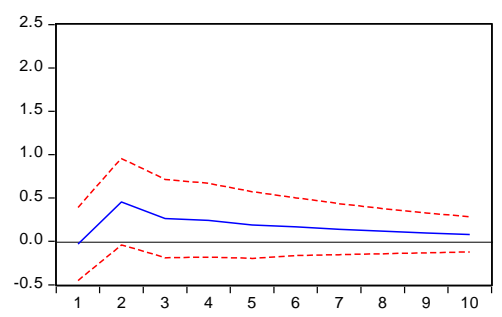

Response of COSPR to GDPG

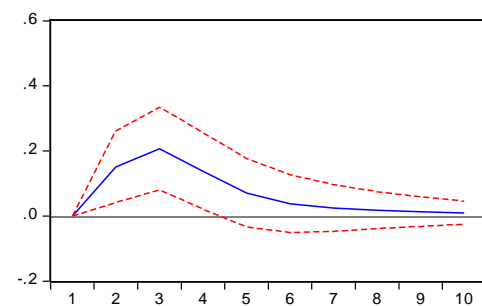

Response of CCONF to GDPG

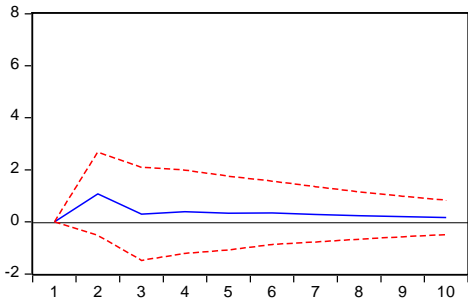

Response of GDPG to GDPG

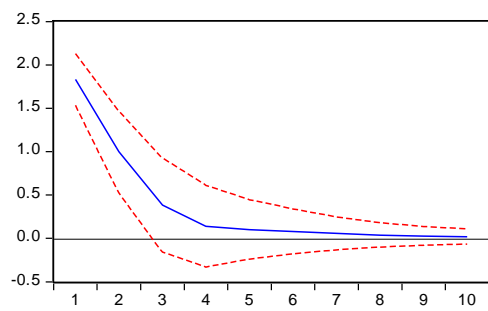

Appendix C: VAR Lag order selection

\begin{tabular}{lllllll}
\hline Lag & LogL & LR & FPE & AIC & SC & HQ \\
\hline 0 & -469.8794 & NA & 122.3542 & 13.32055 & 13.41615 & 13.35856 \\
1 & -416.9350 & 99.92316 & $35.49540^{*}$ & $12.08268^{*}$ & $12.46510^{*}$ & $12.23475^{*}$ \\
2 & -409.4729 & 13.45282 & 37.12511 & 12.12600 & 12.79524 & 12.39213 \\
3 & -407.9526 & 2.612304 & 46.00350 & 12.33669 & 13.29276 & 12.71689 \\
4 & -399.4589 & 13.87710 & 46.98614 & 12.35095 & 13.59383 & 12.84521 \\
5 & -384.4886 & $23.19342^{*}$ & 40.15543 & 12.18278 & 13.71248 & 12.79109 \\
6 & -374.0222 & 15.33110 & 39.16964 & 12.14147 & 13.95799 & 12.86384 \\
7 & -370.8941 & 4.317630 & 47.29605 & 12.30688 & 14.41021 & 13.14331 \\
\hline
\end{tabular}

* indicates lag order selected by the criterion

Appendix D: Structural break test

Sequential F-statistic determined breaks:

$\mathbf{0}$

\begin{tabular}{llll}
\hline Break Test & F-statistic & Scaled F-statistic & Critical Value** $^{* *}$ \\
0 vs. 1 & 5.126898 & 5.126898 & 8.58 \\
\hline
\end{tabular}

* Significant at the 0.05 level. 